\title{
Collection management as risk management
}

\author{
Mary F. Casserly \\ University at Albany Libraries, LI-204, University at Albany, 1400 Washington Avenue, Albany, NY 12222, USA
}

\begin{abstract}
Risk and technological changes are inexorably linked, and librarians, as experts, must communicate these risks to lay persons and develop appropriate risk management strategies. This paper identifies some of the risks to library primacy, library and professional values, collection integrity, and scholarly communication and the information marketplace that those involved in collection development and acquisition of library materials may encounter. The sources of these risks are briefly described, and the author suggests some risk management strategies.

(C) 2004 Elsevier Inc. All rights reserved.
\end{abstract}

Keywords: Professional values; Collection integrity; Scholarly communication; Information marketplace

\section{Introduction}

In his recent article, "Technological Change and the Scholarly Communications Reform Movement," Richard Fyffe brought together the thinking of "risk society" and "technological determinism" theorists to address the management of the risk of loss of scholarly knowledge. He notes that librarians and libraries, if they are to participate in the reform of the scholarly communication process and maintain their credibility and integrity, must inform the members of their academic communities about this risk. Fyffe suggests that one way to do so is to reconceive the traditional collection development policy as "a strategically oriented access-development plan..." which would "articulate, for each disciplinary program, the roles that local collections, remotely hosted digital files, and document delivery services will play in providing information [1]." The collection development policy would, in fact, become a rhetorical instrument for documenting the sources of long- and short-term risk to scholarly information and for communicating the "limits of our control over information services [2]."

E-mail address: mcasserly@uamail.albany.edu. 
This paper acknowledges Fyffe's point: risk and technological changes are inexorably linked, and librarians, as experts, must communicate these risks to lay persons and develop appropriate risk management strategies. Whereas Fyffe focused on the risk of scholarly information loss, this paper will identify some of the risks to library primacy and values, as well as to scholarly communication and the information marketplace that those in collections and acquisitions may encounter. The paper will then briefly describe the sources of these risks and suggest some strategies for managing and communicating them.

\section{Risk to library primacy}

Academic libraries address their mission to support research and teaching by building collections and developing services intended to meet the information needs of their constituencies. Collection managers try to assure a close fit between information supply and user demand with collection development policies and collection evaluations, as well as by allocating acquisition budgets to reflect institutional priorities. These efforts are intended to assure that the academic library collection will be the first resource their students and faculty will consult. In 2001 research libraries affiliated with the Association of Research Libraries invested $\$ 944$ million to protect and further collection primacy [3].

Academic library collections that do not meet user needs and expectations or that are less convenient or useful than competing services can become marginalized. Such marginalization can lead to a spiral of loss of funding resulting in a decrease in usefulness, followed by further erosion of fiscal support. The decline in the quality of the collection in the short run can also lead, over the longer term, to risks to some of the basic values for which libraries stand and the basic functions they serve. Sources of risk to library primacy include changing constituent needs and competition from emerging information services.

\subsection{Changing constituent needs and expectations}

Those entering the academic community today have very different expectations regarding information, its access, and its use than those who came of age in the print environment. By the time this year's college freshmen entered kindergarten, the World Wide Web had already been released by the European Organisation for Nuclear Research (CERN); the next year, when they were in first grade, the term "surfing the Internet" was coined [4]. These freshmen are the "cut and paste" generation, and their education and their life experience have been profoundly influenced, if not dominated, by technology.

Several recent studies lend insight into student research behaviors, use of technology, and expectations. The 2002 study conducted by the Digital Library Federation and Outsell, Inc. characterizes the academic community as "far from homogeneous in its level of sophistication, information needs and infrastructure requirements" [5]. Its findings indicate that undergraduates expect to be able to conduct their research online, whereas graduate students and faculty expect to rely on print as well as electronic resources. All three of these 
populations were found to have high standards, expecting rapid delivery of information resources, ease of access, quality, currency, ability to search, coverage, and printing [6].

The OCLC study on college students' information habits and use of campus library Web sites also provides evidence that while undergraduate library constituents value remote access and accurate information, they also want face-to-face interaction when they need assistance, and they do not want to pay for the information they access. This study found that college students are heavy users of the Internet and that they perceive libraries as lacking the customer orientation they expect [7].

Over the past few years, a number of authors have used Postmodernism as a context in which to further our understanding of student and faculty needs and expectations, as well as to develop new, and reengineer existing, library services [8]. The central theme of Postmodernism is that reality is a social construct that is "made," not "found." As such, it is a rejection of the predictability, certainty, control, order, and absolute truths that characterized the Modern Era or Age of Reason [9]. "It particularizes rather than generalizes, thus privileging social, cultural, political and philosophical diversity" [10].

As it pertains to academic library services, Postmodernism is characterized by consumerism, superficiality, and knowledge fragmentation. When approaching research, Postmodern students value information that is least costly and most convenient; they evidence little interest in understanding how the research process or their research tools and resources work. They accept Postmodernism's emphasis on subjectivity and, therefore, they may lack objective, critical thinking skills [11].

The professoriate is, likewise, increasingly the product of Postmodernism. Frank and Howell characterize the postmodern faculty as technologically savvy, pedagogically experimental, interested in interdisciplinary scholarship, and comfortable with varied or multiple perspectives as well as ambiguous, or chaotic, situations. They are less hierarchical and more collaborative than their Modern colleagues, and their teaching styles reflect these characteristics [12]. Postmodern faculty and their students are the products of a visual culture that, in James Marcum's view, has now evolved into a visual ecology. He describes this as "a comprehensive and continuous participatory event, a universe of action, and a world of knowledge and learning rather than of information transfer [13]."

Academic librarians are just beginning to explore the extent to which our incoming students and faculty differ from those with whom we have previously worked. Recent studies confirm that there is a change in how people use libraries, but "these behaviors have not yet sorted themselves into predictable patterns" [14]. It is clear, however, that entering students and new faculty have expectations and needs for information and services that go well beyond providing any time/any place access to existing collections and services. It is also the case that to address these needs, libraries must be flexible, responsive, and collaborative.

\subsection{Competing information services and resources}

Many academic library constituents have multiple associations, affiliations, and opportunities to acquire information. They may use some or all of these-along with, 
or in place of, their academic library-to fill their information needs. Bell identifies both external and internal information marketplace library competitors. External competitors are those that are not affiliated with the academic institution, such as Questia, XanEdu, and Jones e-global. Internal competitors constitute a subtler, and probably unintentional, form of competition. They include Blackboard, WebCT, and Campus Pipeline. These products and services are frequently chosen and supplied by the campus information technology group, often without input from the library. All of these products offer students and/or faculty choices for accessing information and alternatives to their academic library [15]. For faculty and graduate students, alternative access to information resources can also come from professional associations that sell their electronic publications, databases, and search engines directly to their members.

The Web is arguably the academic library collection's most formidable competitor. For Postmodern students and faculty, the Web is convenient and ubiquitous. They are always "there" using it for entertainment, shopping, and communicating. The Internet and American Life Project confirms the suspicions of many: college students use technology more heavily than does the general population. The study found that the majority own a computer, check their e-mail daily, have more than one e-mail address, browse the Internet for fun, and download music. Almost three quarters of college students surveyed indicated that they use the Internet more than the library when conducting their research [16]. Given their preference for on-line resources and their confidence in their ability to navigate the Internet, it is easy to envision a future in which students regard the Internet as their primary information resource.

\subsection{Library primacy-strategies for managing risk}

1. Enter into discussions with faculty concerning their teaching methodologies, what they require of their students, and how well the library collection is meeting their needs. These discussions should be an on-going and expanded dialog, not only about the collection, but also about pedagogy and teaching and learning styles. The knowledge gleaned from these interactions should be shared with library staff and synthesized so that trends can be identified.

2. Identify user expectations, needs, and the extent to which library collections and services are meeting them by using assessment tools such as, but not limited to, LibQUAL $+{ }^{\mathrm{TM}}$ [http://www.libqual.org]. Such tools can help identify areas of unmet expectations and predict how collection management should look in the future.

3. Adopt some of the strategies suggested by Bell for dealing with competing information services and resources, including:

3.1. Scan the environment. Environmental scanning should be part of the planning process and should include acquiring information from a much wider range of fields than the library and education literatures. To assess the risk to the collection from competitors, research and then test competing products and services thoroughly. 
3.2. Armed with knowledge about real and potential competitors, market the library's collections and services. Librarians have an advantage over outside competitors in that they know their constituents well and they have easy access to them.

3.3. Provide a level of service, along with the information resources, that adds value to the collection. While commercial products must be somewhat generic to be widely sold, libraries are able to focus exclusively on their constituents and develop collections and services that address specific, perhaps even unique, local needs.

3.4. Build partnerships with commercial content providers that will enable students and faculty to use their information resources when that content is not available in the library's collection [17].

4. Hire staff that will be able to meet future, as well as current, faculty and student needs. During the hiring process, focus on desired traits rather than on a "laundry list of requirements" [18]. Look for some of the traditional training and skills that address current needs, but also consider a candidate's "capacity to learn, ability to adapt to change, and willingness to innovate" [19]. Hire those who have nontraditional training and/or experience. Use internships and residencies as ways of recruiting such individuals and exploring how they might contribute to the library's collection management efforts.

5. Develop staff skills and staff awareness of the changing educational environment. The gap between what collection management staff believes their priorities to be and the expectations of their faculty and students occurs both when staff are unaware of constituent needs and expectations and when they are aware but lack the skills and training to meet them. Staff awareness of changing needs and expectations will enable them to contribute to the development of a postmodern academic library.

6. Communicate with library schools and professional associations. Collection managers, as potential employers, need to provide input into graduate program curriculum design to assure an appropriately trained talent pool from which to hire.

\section{Risk to library and professional values and collection integrity}

Attempts to document core or ethical values for the library profession have generated lively debate. However, most librarians would agree that their professional ethics include protecting their constituents' privacy, providing equal access to information, and making available diverse ideas, opinions, and perspectives. Librarians also act as stewards of the human record and they apply a rational, scientific approach to this task [20]. Their commitment to service overlays these values. As Rubin notes, "This activity, bringing knowledge to people and the society, is the sine qua non of the profession" [21]. The collection manager operationalizes stewardship, rationalism, and service by developing a collection that has integrity. It contains, or provides access to, appropriate and authoritative information, and its users find both its content, and the means of accessing that content, to be predictable and reliable. 


\subsection{Monitoring collection use}

Collection managers often complain that although publishers and database providers collect and distribute great quantities of statistics about the use of their products, interpretation and comparison are often difficult. Although collection managers have continued to demand more and better use statistics from their content providers, they remain concerned about privacy.

Librarians and content providers have collaborated on the development of several sets of guidelines through the International Coalition of Library Consortia (ICOLC) that address concerns about privacy and confidentiality of use data, and the American Library Association has issued "Guidelines for Developing a Library Privacy Policy" in draft form [22]. All these documents focus on personally identifiable information, an issue of growing importance as more and more database providers offer SDI, table of content, and other customized services which require that participants provide data about their research and information interests which then reside on these providers' servers. However, collection managers have paid relatively little attention to the aggregated use data that content providers are able to generate and analyze. Guédon observes that large publishers who provide their resources to large consortia have a unique observation post on usage and research. They are able to analyze "where interesting science is happening, where breakthroughs are likely to occur..." [23]. Even smaller vendors and those selling to smaller consortia and individual libraries have the ability to collect and aggregate data that is similarly revealing.

Although concerned about content providers' abilities to monitor use of their products and the attendant risks to privacy, the library profession knows very little about the amount of use data content providers collect, their ability to trace it back to individuals and aggregate it, how long they keep it, under what conditions they might share it with other publishers, and what happens to it when publishers merge, are acquired, or go out of business. Libraries have encouraged information suppliers to monitor use of information by students, faculty, and staff without any assurance that these suppliers share the library profession's respect for, and commitment to, user privacy and confidentiality.

\subsection{Publisher and vendor mergers}

The library profession has expressed serious concerns about the ownership of content by an ever-shrinking universe of commercial publishers. This concentration enables publishers to raise prices above the rate of inflation and thereby threatens one of the profession's core values, equal access to information [24]. In addition, whereas in the print environment publisher mergers and acquisitions do not affect the accessibility of titles already published, the consolidation of digital information resources in the hands of fewer and fewer publishers and database providers poses risks to the preservation of the human record. Publisher mergers and acquisitions can result in the disappearances of acquired content. They can also affect the usability of digital content due to changes in the interface through which acquired content is accessed and/or the way acquired and existing content are merged or juxtaposed. 


\subsection{Intellectual property and copyright_changing legislation}

Copyright was originally conceived as the means of granting authors a period of monopoly as an incentive to further create. One of its principles was that works not specifically protected were available to be used by others. Recent legislation, including the Digital Millennium Copyright Act, the Copyright Term Extension Act, and the Uniform Computer Information Transaction Act, have so altered intellectual property rights that they threaten the free flow of information and run counter to long-established principles of fair use and first sale. They also significantly delay the movement of works into the public domain [25].

The library community has defined access to mean, not only the right to read and browse published works, but also the right to use works in ways that are allowed by copyright exceptions: specifically for fair use purposes, for preservation of library materials for use by future generations, and for use in classroom teaching [26]. These are the "public and open spaces of knowledge" [27] and the library profession has worked hard to create them and continues to advocate preserving them. However, in the digital environment, these commons are increasingly threatened. Digital publishers and content providers often require libraries to sign agreements that restrict the libraries' ability to use their products for interlibrary loan, as well as the libraries' rights to preserve and archive parts of them. Further, by using digital rights management systems, these publishers and content providers can enforce use restrictions, such as on copying and downloading, that are more stringent than those that copyright law would impose [28]. Cheverie observes that "In an effort to secure market advantage and to eliminate piracy, content industries want to use technology to create digital fences that will enclose not only their works but also large portions of the public domain" [29]. In particular, the pay per view model or transaction cost model, while optimizing copyright, undermines access, restrains use and reuse of content, and ultimately restricts opportunities to use content to create new knowledge and innovate.

\subsection{Collection content-unplanned deletions and additions}

On many levels and for many reasons libraries simply do not have the same degree of control over the content in their digital resources as they have over content in their traditional resources. Providers of digital information resources are able to add content to or, more often, delete content from their products without their customers' consent. Libraries are frequently notified after the fact or given very little advance notice of these actions. On occasion, no notification is issued; libraries and their users simply discover the content change. For libraries that receive access to digital resources purchased by a statewide consortium or university system, unplanned changes in collection content can also occur on the product level. Unplanned content changes affect the collection's reliability and integrity and content removal may pose risks to the library profession's commitment to preservation.

\subsection{1. e-Journals}

Many of the cases of content removal by e-journal publishers are copyright-related. Typically, the removal occurs when publishers find, after they have already done so, that they 
do not have the rights to republish electronically the content they originally published in paper. Less frequently, publishers remove content in response to research errors, plagiarism, and fraud. This practice is contrary to traditional scholarly communication practice and it violates the library's commitment to preserve the historical record with all its flaws [30].

\subsubsection{Aggregated databases}

Disaggregation, or the removal of content from an aggregated database by its creator or owner, occurs for a variety of reasons - often economic but sometimes philosophical in nature. Disaggregation can transform an aggregated database from a key, to a marginal, resource and, since libraries are rarely compensated for content removal, it can also pose financial challenges. If the lost content is an important resource for its users the library may have to resubscribe to it from another, generally more expensive, source.

\subsubsection{System and statewide acquisitions}

It is increasingly common for libraries to access databases and other digital content through subscriptions that are negotiated and paid for by overarching agencies. Acquisitions by such agencies are generally intended to assure equal access and are aimed at addressing information needs that are seen as basic, or common, to all member libraries. When they occur among public institutions, they are frequently cited as examples of effective use of tax dollars.

The provision of electronic resources across a system or state is generally regarded as a social good, and these efforts have enriched many library collections. However, information resources and content provided by overarching agencies can be a mixed blessing and can affect the overall integrity of the academic library collection. The process of selecting these resources varies, as does the level of participation by the affected libraries. Individual libraries may have some input into selection decisions but they do not control them. Titles selected may duplicate content already paid for by an individual library, provide needed content but through an unsatisfactory interface, or may be accompanied by conditions or unfunded mandates such as a requirement to maintain a minimum expenditure level. Often libraries are unable to cancel their duplicate subscriptions and make other adjustments because of differences in subscription periods and lack of adequate notice of changes to the systemwide collection.

\subsection{Library and professional values-strategies for managing risks}

1. Ask publishers and database providers for those statistics that are truly needed and useful. Insist on the confidentiality of these data. Usage data should be available only to the designated individuals within an institution and publishers and database providers should be able to assure their customers that they will not sell the usage data they collect. Librarians and publishers should work together to develop privacy guidelines for aggregated use data and adherence to such guidelines should be included in licensing agreements. Collection managers should understand and convey to users the data collection policies of their content providers. 
2. Communicate concerns about risks to basic library and professional values to publishers and database providers and their sales representatives. Participate in user groups, listservs, and conferences and symposia at which publishers and content providers are present. At the same time, expand collection development strategies to include initiatives to broaden access to research and data such as the National Digital Library of Theses and Dissertations and institutional repositories.

3. Participate in system and statewide collection decisions. Having input into the titles being selected, renewed and cancelled may increase the chances that provided resources will meet local needs.

4. Foster an understanding among state and systemwide resource providers that information needs among libraries - even those of the same type-differ. In his recent study of NorthEast Research Libraries Consortium (NERL) members' uses of a large e-journal collection Davis found that the more similar libraries are in size and mission, the more alike their collection needs and uses will be [31]. These findings suggest that the multitype library consortia approach, such as purchasing access to a database or group of databases for all libraries in the state, may not be as effective as a menu approach in which libraries are able to select from a list of supported resources those titles that will best meet their local information needs.

5. Become consumer activists or at least more vocal consumers. Use buying power to make it clear to publishers and database aggregators that they need to provide stable content and be clear about what their databases will include and exclude during the subscription period. Removal of significant content during the course of a subscription should be accompanied by an adjustment in the subscription price.

\section{Risks to scholarly communication and the information marketplace}

"Scholarly Communication" can be defined as the process by which scholarly works are produced, distributed, preserved, and used. Although this term is often used synonymously with "scholarly publishing" - particularly in the context of the crisis in journal pricing-it actually encompasses the totality of what occurs between the creation and consumption of a scholarly work. The information marketplace and scholarly communication intersect at the point where a scholarly work is distributed or sold. The risks to scholarly communication and the information marketplace begin at the point at which the scholarship is documented, and are related to who sells scholarly content, who buys it, and how these transactions are accomplished.

\subsection{Documentation of scholarly works}

In speaking about electronic scholarly publishing and format conventions and practices in written communications, Clifford Lynch observed, "We are now going to have to recapitulate - quickly - the evolution of conventions for the digital world paralleling those that have arisen over four centuries during which we have developed our expectations and practices 
around printed books and journals" [32]. Current citation practices for documenting electronic information sources illustrate Lynch's point.

Appropriate and accurate citations document the origins of scholarly works and help researchers assess the validity of works in their fields. Increasingly, scholars rely on, and in their publications cite, documents and information on the Web. Although guidelines for citing Web documents have been developed by the Modern Language Association and the American Psychological Association, to name just two, they have not yet been well integrated into practice. A study of citations appearing in articles published in the library and information science literature in 1999 and 2000 provides evidence of this. In that study only $43 \%$ of the citations that contained URLs also contained full bibliographic information, 51\% contained only partial bibliographic information, and $6 \%$ consisted of only a URL. Further, few of the instructions to the authors by the 34 journals studied included instructions for citing digital resources [33].

\subsection{More is better}

Striving to acquire the greatest quantity of content for the least amount of money is a behavior that is at once laudable and risky. Many of the reasons that it is a risk to scholarly communication and the information marketplace have been put forth quite eloquently by Ken Frazier in his examination of "The Big Deal." Frazier observes that as libraries pursue "Big Deals" - that is, license agreements in which access is gained to all of a publisher's output for a price based on current subscriptions - they acquire more content for less money in the short run, but they risk weakening "the power of librarians and consumers to influence scholarly communication systems in the future [34]."

It is worth noting that the pursuit of more information or more publications for less money takes place in most consortia purchases, many of which would not necessarily be considered "Big Deals." Yet these, too, pose risks to scholarly communication. Consortia generally find it more efficient to use their limited staff time and effort to focus on large collections of content as opposed to individual titles like those arising from scholarly initiatives or published by small nonprofit associations. Landesman and Van Reenen argue that this tendency is incongruent with the library community's efforts to reform scholarly communication by encouraging small journals and other scholarly publishing initiatives. This focus on large information content results in price differentials that shift costs to smaller libraries, a creeping dominance of large publishers' products in the library budgets, and an increase in visibility that will drive usage. Eventually, the consortia participants must cancel titles from the smaller, more library-friendly, publishers in order to preserve their access to the consortial titles [35].

\subsection{Disintermediation}

The information marketplace includes libraries as buyers, publishers as sellers, and intermediaries who provide both products and services. The roles of all of these participants are important to the efficiency and effectiveness of the scholarly communication process. 
When publishers insist on selling directly to libraries, one such intermediary, the subscription agent, is by-passed. Few publishers have the ability to adequately provide the servicescustomer support, electronic interfacing and invoicing, item-level billing, etc. - offered by the subscription agent, and the effects on libraries and, one would also think, on these publishers, are decidedly negative.

Libraries have long tolerated the relatively small number of book publishers who insist on selling directly to them or structure their pricing so that direct purchase is very advantageous. Libraries do so because, despite the fact that the service they receive from these publishers is often inferior to that provided by their book jobbers, the number of publications involved constitutes only a small percentage of their annual book acquisitions. However, libraries cannot regard large publishers of electronic journals who require direct purchases so benignly. Many libraries subscribe to hundreds of their journals. Service from these publishers falls short of what libraries are used to receiving from their subscription agents in many ways, and allocating library staff to address these shortcomings is expensive. In addition, subscription agents respond to the decrease in their volume of business by raising service charges or lowering discounts. The overall effect is that libraries spend more money and get less service. This disintermediation of subscription agents is what Frazier referred to as "a hidden price increase for subscribing to the Big Deal" [36].

\subsection{Content acquisition}

Those writing about "The Big Deal" have adequately covered many of the risks associated with market dominance by a small number of publishers. They have identified pricing discrepancies, potential skewing of user demand, and the consequent effect of inflating the impact factors of these publishers' journals [37]. However, the information marketplace is also dominated by a small number of aggregator database publishers who, in order to differentiate their products from those of the other publishers, pursue exclusive licenses to publish content from scholarly and professional societies and other nonprofit publishers. The revenue offered to these publishers may provide much needed immediate income, but, over the long term, such exclusive agreements may also run counter to the library community's interests in scholarly communication reform. Such agreements prevent publishers from placing their texts in a wide range of electronic databases and/or developing their own, discipline specific, databases. To the extent that these exclusive agreements reduce or eliminate embargo periods, they may also threaten the nonprofit publishers' print subscription base. As libraries drop their subscriptions to the print journals whose content is included in aggregated databases, these publishers become increasingly reliant on revenue from aggregators which further restricts access to their content.

\subsection{Scholarly communications and the information marketplace-strategies for managing risk}

1. Work with commercial publishers and professional associations as authors, editors, and members to establish and enforce sound scholarly citation and documentation practices. 
Encourage this by making the quality of a publication's citations and documentation practices a selection criterion.

2. Encourage the consortia to look at single titles or collections of works from smaller publishers. Project Muse [http://muse.jhu.edu] and Project Euclid [http://projecteuclid.org/ Dienst/UI/1.0/Home] are examples of such collections.

3. Promote competition among publishers and alternative access to locally produced content. Support efforts, such as SPARC [http:/www.arl.org/sparc/home/index.asp?page=0], that encourage competition among publishers. Develop local collections and archives that provide access to publications and information created on campus.

4. Cancel individual titles available through aggregated databases judiciously. Consider continuing to support titles from, at least, the nonprofit publishers.

5. Become more assertive as negotiators and as customers. Be willing to say "no" when a contract or license is not satisfactory. Further, do not settle for poor service or for promises not delivered. Chuck Hamaker suggests some strategies for responding to these shortcomings. These include releasing funds for journals and electronic services only after the library has verified that content is complete and promised features are provided [38].

6. Weigh all the costs of a "Deal." Library staff investments to compensate for missing service are expensive. Work with subscription agents and publishers to adapt existing services or develop new ones that will provide the support libraries need for consortial purchases including "Big Deals."

7. Make time to talk to faculty about what is happening in scholarly communication. If they understand the issues they are less likely to object if their library decides not to provide access to some of the "Deals"_-big or small.

\section{Conclusion}

Risk, while connoting serious consequences - beyond those that might be associated with failing to address an "issue" or meet a "challenge," is a healthy, important part of progress and change. For this reason, collection managers must work knowledgeably to manage, rather than avoid, it. Although the risk management techniques suggested here address a wide variety of concerns, they also have some common themes. Collection managers must continue to communicate with their constituents about their needs, but these conversations should be expanded in scope. It is increasingly important for them to focus these conversations on changing expectations as well as convey information about changes in scholarly communication, the information marketplace and risks to professional and societal values. Collection managers must also become more proactive consumers, conveying to their publishers and content providers concerns about privacy, collection stability and reliability, and access. Further, collection managers must be prepared to discontinue purchasing or subscribing to the information resources offered by publishers and content providers who, over the long term, do not address these concerns. Finally, collections managers need to play an active role in local and national efforts to encourage competition and create alternative access to information. 
A shorter version of this paper was presented by the author at The Acquisitions Institute at Timberline Lodge, May 17-20, 2003.

\section{References}

[1] Fyffe, R. (2002). Technological change and the scholarly communications reform movement-Reflections on Castells and Gidden. Library Resources and Technical Services, 46(2), 59.

[2] Ibid.

[3] Association of Research Libraries (2002). ARL statistics 2000-01 (p. 38). Chicago, IL: Author.

[4] Polly, J. A. (1994, November). The nascence of surfing the Internet. Retrieved February 26, 2003, from http://www.netmom.com/about/birth.shtml.

[5] Friedlander, A. (2002, November 7). Dimensions and use of the scholarly information environment: Introduction to a data set assembled by the Digital Library Federation and Outsell, Inc. (p. 18). Retrieved July 1, 2003, from the Council on Library and Information Resources Web site at http://www.clir.org/pubs/reports/ pub110/contents.html.

[6] Ibid, p. 9.

[7] Harris Interactive (2002, June). How academic librarians can influence students' web-based information choices: OCLC white paper on the information habits of college students. Washington, DC: OCLC Online Computer Center.

[8] Ray, K. L. (2001). The postmodern library in an age of assessment. In H. A. Thompson (Ed.), Crossing the Divide: Proceedings of the Tenth National Conference of the Association of College and Research Libraries, March 15-18, 2001 (pp. 250-254). Dublin, OH: Association of College and Research Libraries;

Propas, S., \& Reich, V. (1995). Postmodern acquisitions. Library Acquisitions: Practice and Theory, 19(1), 43-48;

Harley, B., Dreger, M., \& Knobloch, P. (2001). The postmodern condition: Students, the web, and academic library services. Reference Services Review, 29(1), 23-32;

Hubbard, T. E. (1995). Bibliographic instruction and postmodern pedagogy. Library Trends, 44(2), 439-452; Muddiman, D. (1999). Towards a postmodern context for information and library education. Education for Information, 17(1), 1-19;

Radford, G. P. (1998). Flaubert, Foucault, and the Bibliotheque Fantastique: Toward a postmodern epistemology for library science. Library Trends, 46(4), 616-634.

[9] Ray, p. 251.

[10] Hubbard, p. 442.

[11] Harley.

[12] Frank, D. G., \& Howell, E. (2003). New relationships in academe-Opportunities for vitality and relevance. College and Research Library News, 64(1), 24-27.

[13] Marcum, J. W. (2002). Beyond virtual culture: The challenge of visual ecology. portal: Librarians and the Academy, 2(2), 189.

[14] Association of Research Libraries (2002, December). Collections \& access for the 21st century scholar: Changing roles of research libraries-A report from the ARL Collections \& Access Issues Taskforce. ARL Bimonthly Report, vol. 225 (p. 5).

[15] Bell, S. J. (2002). New information marketplace competitors: Issues and strategies for academic libraries. portal: Librarians and the Academy, 2(2), 277-303.

[16] Jones, S. (2002, September 15). The Internet goes to college: How students are living in the future with today's technology. Retrieved July 24, 2003, from the Pew Internet and American Life Project Web site at http://www.pewinternet.org/reports/toc.asp?Report=71.

[17] Bell. 
[18] Raschke, G. K. (2003). Hiring and recruitment practices in academic libraries: Problems and solutions. portal: Libraries and the Academy, 3(1), 61.

[19] Ibid.

[20] Gorman, M. (2000). Our enduring values: Librarianship in the 21st century. Chicago, IL: American Library Association.

[21] Rubin, R. E. (2000). Foundations of library and information science (p. 248). Chicago: Neal-Schuman.

[22] International Coalition of Library Consortia (2001, December). Guidelines for statistical measures of usage of Web-based information resources. Retrieved July 24, 2003, from the Yale University Library Web site at http://www.library.yale.edu/consortia/2001webstats.htm;

International Coalition of Library Consortia (2002, July). Privacy guidelines for electronic resources vendors (Retrieved July 24, 2003, from the Yale University Library Web site) Available at: http://www.library.yale.edu/ consortia/2002privacyguidelines.html;

American Library Association Intellectual Freedom Committee (2003). Guidelines for developing a library privacy policy (Revised draft 6-13-03).

[23] Guédon, J. (2001, October). Beyond core journals and licenses: The path to reform scientific publishing. ARL Bimonthly Report, vol. 218 (p. 5).

[24] Susman, T. M., \& Carter, D. J. (2003, June). Publisher mergers: A consumer-based approach to antitrust analysis. New York: Information Access Alliance.

[25] Adler, P. (2001). Copyright and intellectual property legislation and related activities: New challenges for libraries. In S. H. Lee (Ed.), Impact of digital technology on library collections and resource sharing (pp. 107-118). New York, NY: Haworth Press, Co-published simultaneously in Journal of Library Administration, 35(3), 2001.

[26] Cheverie, J. F. (2002). The changing economics of information, technological development, and copyright protection: What are the consequences for the public domain? Journal of Academic Librarianship, 28(5), 330 .

[27] Guédon, p. 1.

[28] Vaidhyanathan, S. (2002, August 2). Copyright as cudgel. Chronicle of Higher Education, B7.

[29] Cheverie, p. 329.

[30] Foster, A. L. (2003, January 10). Elseviers's vanishing act. Chronicle of Higher Education, A27.

[31] Davis, P. M. (2002). Patterns in electronic journal usage: Challenging the composition of geographic consortia. College and Research Libraries, 63(6), 484-497.

[32] Lynch, C. (2002, December 1). Academic publishing in the digital realm: An interview with Clifford Lynch. Syllabus. Retrieved July 25, 2003, from the World Wide Web at http://www.syllabus.com/article. asp?id $=6983$.

[33] Casserly, M. F., \& Bird, J. E. (2003). Web citation availability: Analysis and implications for scholarship. College and Research Libraries, 64(4), 300-317.

[34] Frazier, K. (2001, March). The librarians' dilemma: Contemplating the costs of the "big deal". D-Lib Magazine, 7(3). Retrieved July 25, 2003, from http://www.dlib.org/dlib/march01/frazier/03frazier.html.

[35] Landesman, M., \& Van Reenen, J. (2000, December). Creating congruence. JEP: The Journal of Electronic Publishing, 6(2). Retrieved July 25, from http://www.press.umich.edu/jep/06-02/landesman.html.

[36] Frazier.

[37] Ibid.; Landesman \& VanReenen (2000).

[38] Hamaker, C. (2003, January). The new Elsevier's surprising service problems. The Charleston Advisor, 4(3). Retrieved July 25, 2003, from http://www.charlestonco.com/features.cfm?id=121\&type=ed. 